\section{MÉTODOS PARTICIPATIVOS PARA DIAGNÓSTICO DA SOBERANIA ALIMENTAR NO ASSENTAMENTO RURAL PA SÃO FRANCISCO, RONDONÓPOLIS - MT}

Hebert Teixeira Cândido José Adolfo Iriam Sturza ${ }^{2}$

RESUMo: Embora a agricultura tenha iniciado com o intuito de alimentar e nutrir o ser humano, com o passar do tempo os alimentos se transformaram em mercadorias, onde suas funções principais foram esquecidas. Atualmente a produção agrícola atingiu níveis de produção nunca visto, contudo, cerca de 1 bilhão de pessoas ainda passam fome no mundo. Nesse sentido, a agricultura familiar desponta como o modelo de produção capaz de suprir as necessidades alimentares da população mundial e produzir de um modo mais harmônico quando comparada a agricultura industrial. Nos anos 90 surgiu o conceito de Soberania Alimentar, o qual além do acesso a um alimento de qualidade preza pela independência dos povos em sua produção, sendo necessários para isso a preservação e o acesso aos recursos. Este estudo buscou diagnosticar a situação quanto a soberania alimentar no Assentamento São Francisco a partir de ferramentas de Diagnóstico Rural Participativo. O estudo foi realizado com alunos de EJA frequentadores de uma escola rural ao longo de 8 visitas ao assentamento durante o horário das aulas que foram cedidas pela professora responsável pela turma. As visitas ocorreram de março a agosto de 2017. A partir do estudo verificou-se que os moradores do assentamento possuem controle sobre sua produção (principalmente autoconsumo) e acesso a grande parte dos recursos necessários para as atividades, contudo, devido ao envelhecimento da população não se sabe se esse quadro será transmitido às gerações futuras.

Palavras-Chave: Assentamento Rural; Diagnóstico Rural Participativo. Indicadores.

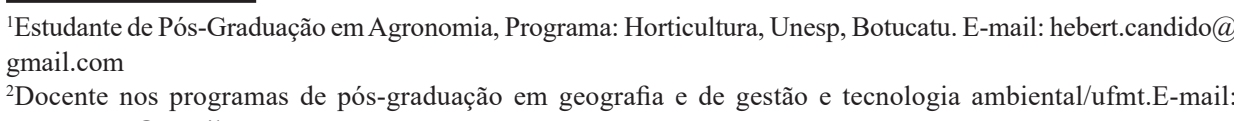

ABSTRACT: Although agriculture original intent was to feed and nourish the human being, food has become commodity over the time. In fact, actual agricultural production has reached unprecedented levels of production, but about 1 billion people still starve worldwide. In this sense, family agriculture emerges as the model of production capable of meeting food needs of population while meeting a more harmonic production when compared to industrial agriculture. Thus, in the 1990s the concept of food sovereignty arose, which not only allowed people to access to quality food, but also to independence values concerning production, and preservation of resources. In this context, this study aimed to diagnose food sovereignty in the São Francisco settlement from the tools of Participative Rural Appraisal (PRA). For this, some categories of indicators were previously selected. The study was carried out on EJA students attending rural school during 8 visits to the settlement at class time. Visits occurred from March to August 2017. From the study, it was verified control of settlement inhabitant over their production (mainly self-consumption) and access to much of the resources needed for the activities. However, aging of the population poses uncertainty whether this framework will be passed on to future generations.

KEYwORDs: Rural Settlement; Rural Participatory Appraisal; Indicators.

\section{INTRODUÇ̃̃o}

A ciência estima que as primeiras atividades agrícolas tenham se iniciado há aproximadamente 10.000 anos, a partir do momento em que o homem conseguiu compreender a relação semente-planta-semente. Essa percepção permitiu a humanidade produzir seus próprios alimentos, o que culminou com uma mudança em sua própria forma de vida, deixando para trás o nomadismo para viver de forma sedentária, deixando para trás seus hábitos de caçador e coletor, para cultivar plantas e criar animais (CARVALHO; NAKAGAWA, 2000). No entanto, essa mudança não foi universal nem repentina, restringiu-se a algumas sociedades, pouco difundidas e bastante dispersas umas das outras, as quais são assim chamadas -, primeiros centros de origem da revolução agrícola neolítica. Nesses centros ocorreram as primeiras domesticações de espécies vegetais, facilitadas pelo emprego de ferramentas fabricadas em pedra polida em suas atividades agrícolas (MAZOYER; ROUDART, 2010).

Embora a agricultura tenha se iniciado como uma atividade produtora de alimentos, em muitas regiões esses produtos foram convertidos em 
mercadorias, esquecendo-se suas funções básicas de alimentar e nutrir (PENGUE, 2005). Nesses locais onde a agricultura se desenvolveu por meio do pacote tecnológico introduzido junto à política da revolução verde, a qual contribuiu para o aumento da produção, houve também uma queda no preço. Dessa forma, foram excluídos aqueles pequenos agricultores que não puderam ter acesso a esse pacote tecnológico, pois se tornou inviável a produção desses agricultores (MAZOYER; ROUDART, 2010). Atualmente a capacidade de produzir alimentos atingiu um nível nunca visto antes, no entanto uma em cada sete pessoas não come diariamente e, deste total, metade são crianças. Na América Latina, estima-se que a situação de fome atinge 49 milhões de pessoas (CARDOSO, 2013). Nesse sentido, a agricultura familiar desponta como um tipo de exploração agrícola com potencial para suprir as necessidades alimentares, por meio de uma produção bastante diversificada, utilizando mão de obra familiar, conhecimentos tradicionais e explorando pequenas parcelas de terras; essa agricultura é responsável pela produção de cerca de $80 \%$ dos alimentos na Ásia e na África Subsaariana e por empregar aproximadamente $43 \%$ da mão de obra agrícola nos países em desenvolvimento (FAO, 2013). No ano de 1996 um novo conceito passou a ser debatido em reuniões da FAO (Organização das Nações Unidas para Agricultura e Alimentação), a soberania alimentar. Esse conceito se contrapõe ao conceito de segurança alimentar, pois não só discute o acesso ao alimento, mas valoriza a tradição cultural de um povo e preza pela autonomia dos agricultores em sua produção de alimentos. Em outras palavras, a soberania alimentar visa à construção de um cenário que permita ao agricultor escolher seus próprios alimentos, manter em suas mãos a capacidade de produção e os recursos biológicos necessários, ou seja, produzir e se alimentar com produtos passíveis de serem produzidos localmente, onde a necessidade de insumos externos é nula, ou muito baixa.

No contexto apresentado, o presente trabalho propôs estudar e discutir o acesso aos alimentos e aos recursos disponíveis para essa produção no Assentamento Rural PA São Francisco. As atividades se desenvolveram por meio de práticas participativas, onde as discussões foram direcionadas com base em certas categorias de indicadores. Espera-se que além da compreensão da realidade enfrentada por essas pessoas, essas práticas possam contribuir para a promoção da soberania alimentar dessas pessoas, por meio dos diálogos trocados no decorrer das visitas, nos quais se problematizaram os temas propostos.

\section{Caracterização do local de estudo}

Trata-se de uma pesquisa participativa, onde os resultados foram construídos coletivamente com os sujeitos da pesquisa, alunos de EJA (Educação de Jovens e Adultos), sendo esses, não apenas meros forneceram de dados, mas reconhecendo-os como sujeitos de conhecimento (GIL, 1991). Também foi uma pesquisa exploratória onde se utilizou certas categorias de indicadores para se investigar a soberania alimentar dos assentados. O estudo foi realizado com alunos de EJA moradores do Assentamento PA São Francisco que estudam em uma sala ali existente e anexa à Escola Municipal Rural Padre Dionísio Kuduavizcz, localizada no Assentamento Rural - Gleba Cascata. A sede do Assentamento PA São Francisco está localizada a aproximadamente $32 \mathrm{~km}$ (12 em estrada de terra) do Centro da cidade de Rondonópolis - MT. No total foram realizadas 8 visitas, nas quais foram utilizadas diferentes técnicas para coleta de dados. As visitas foram realizadas nos dias 17/03, 24/03, 11/04, 04/05, 11/05, 18/05, 24/05 e 16/08, todas no ano de 2017.

\section{FerRamentas Para COleta de dados}

As coletas de dados ocorreram em visitas durante o horário de aula em dias letivos, por meio da aplicação de diferentes metodologias de diagnostico participativo. Nesta metodologia, o objetivo não é apenas a coleta de informações, mas, proporcionar aos participantes a capacidade de reconhecer situações e a partir desse reconhecimento, eles mesmos pensarem em alternativas para solucioná-los (VERDEJO, 2006). As ferramentas utilizadas foram: observação participante, elaboração de mapas da propriedade, entrevista em grupos focais e escala do tipo Likert. Importante destacar que as ferramentas para coleta de dados não foram escolhidas com grande antecedência, assim, para essa escolha seguiu-se as recomendações de Geilfus (2002) de modo que foram escolhidas de acordo com a dinâmica apresentada pelo grupo de estudado, respeitando suas dificuldades e aptidões, assim como a percepção do investigador quanto à evolução e necessidades da pesquisa.

\section{ESCOLHA DOS INDICADORES}

Os indicadores utilizados na pesquisa foram os propostos por Ortega-Cerdà e Rivera-Ferre (2010). Contudo, trabalhou-se com poucos indicadores, aqueles que após o contato com a realidade do assentamento, e percepção da realidade ali existente, seriam realmente necessários para a 
pesquisa. Dessa forma, utilizou-se Verdejo (2006), ao se evitar o excesso de informação na coleta de dados, de modo que as informações que se deseja obter são definidas anteriormente a saída a campo com base nos objetivos da pesquisa, logo, permite maior atenção nos assuntos mais importantes. Neste contexto, os indicadores escolhidos estão apresentados no quadro abaixo (Quadro 1).

Quadro 1 - Categorias e subcategorias de indicadores utilizadas para a discussão na entrevista em grupo focal.

\begin{tabular}{|l|l|}
\hline \multicolumn{2}{|c|}{ Indicadores } \\
\hline Categoria & Subcategoria \\
\hline Acesso aos recursos & $\begin{array}{l}\text { Vias; eletricidade; escola infantil; área da propriedade; } \\
\text { água; máquinas agrícolas; financiamento agrícola. }\end{array}$ \\
\hline Modelo de produção & $\begin{array}{l}\text { Jovens trabalhando na propriedade; contratação } \\
\text { de trabalhadores; pomares e hortas; plantas } \\
\text { tradicionais; piscicultura; criações de bovinos, } \\
\text { suínos e aves; fertilizantes e agrotóxicos; defensivos } \\
\text { alternativos e adubos orgânicos. }\end{array}$ \\
\hline $\begin{array}{l}\text { Tr a n s f o r m a ç ã o } \\
\text { comercialização }\end{array}$ & $\begin{array}{l}\text { Associação do assentamento; transformações, } \\
\text { artesanatos, atravessadores e feiras-livres. }\end{array}$ \\
\hline $\begin{array}{l}\text { Segurança e consumo } \\
\text { alimentar }\end{array}$ & Discutido nos tópicos de modelo de produção. \\
\hline Políticas Agrárias & Participação em políticas. \\
\hline
\end{tabular}

Fonte: Pesquisa de Campo.

\section{MAPA DA PROPRIEDADE E ESCALA TIPO LIKERT}

A partir da análise dos mapas das propriedades, atividade na qual estiveram presentes nove alunos, de um total de 12 alunos matriculados, percebeu-se que a agricultura não é a principal atividade econômica nesse grupo de pessoas. Essa leitura somada à observação participante foi muito importante para se restringir o número de indicadores que foram utilizados para compor o questionário que foi utilizado, e, os temas que foram discutidos por meio da técnica de entrevista em grupos focais. Os mapas confeccionados também permitiram visualizar o cenário local quanto à existência de poços, fossas, represas, criações de animais, hortas e pomares.

A seguir (Tabela 1), apresentam-se os resultados obtidos por meio do questionário confeccionado por escala do tipo Likert. Optou-se por elaborar essa tabela em três pontos para facilitar a discussão.

Tabela 1- Resultados das respostas obtidas por questionário confeccionado em escala do tipo Likert.

\begin{tabular}{lccc}
\hline \multicolumn{1}{c}{ Como você se sente em relação? } & $\begin{array}{c}\text { Discordo: } \\
\text { totalmente/ em } \\
\text { grande parte/ } \\
\text { parte }\end{array}$ & $\begin{array}{c}\text { Nem concordo } \\
\text { nem discordo }\end{array}$ & $\begin{array}{c}\text { Concordo: } \\
\text { totalmente/ em } \\
\text { grande parte/ } \\
\text { em parte }\end{array}$ \\
\hline A qualidade das vias de acesso ao assentamento & $78 \%$ & $22 \%$ & - \\
A distribuição de eletricidade no assentamento & $33,3 \%$ & $33,3 \%$ & $33,3 \%$ \\
Ao tamanho da propriedade & $33,3 \%$ & $22,2 \%$ & $44,4 \%$ \\
Ao acesso às máquinas agrícolas da associação & $25 \%$ & $37,5 \%$ & $37,5 \%$ \\
A aplicação de agrotóxicos nas atividades desenvolvidas na propriedade & $78 \%$ & $11 \%$ & $11 \%$ \\
Conduta da associação do assentamento & $62,5 \%$ & $25 \%$ & $12,5 \%$ \\
A venda de produtos em feiras e para atravessadores & $12,5 \%$ & $25 \%$ & $62,5 \%$ \\
Ao atual acesso aos financiamentos agrícolas & $62,5 \%$ & $12,5 \%$ & $25 \%$ \\
A assistência técnica recebida & $75 \%$ & $12,5 \%$ & $12,5 \%$ \\
A vida no assentamento & $12,5 \%$ & - & $87,5 \%$ \\
\hline
\end{tabular}

Fonte: Pesquisa de Campo.

\section{ACESSo aOs ReCURSOS}

$\mathrm{Na}$ sequência do trabalho, $2^{\circ}$ visita, aplicou-se a entrevista em grupos focais, estiveram presentes oito alunos nessa atividade, quando foram discutidos os tópicos apresentados pelo Quadro 1. Sendo assim, seguindo as ordens das categorias discutidas, destacam-se as seguintes respostas:

A partir dos resultados obtidos quanto à categoria acesso aos recursos, verificou-se que as vias de acesso são apontadas como uma das principais dificuldades encontradas pelos moradores do assentamento, este resultado foi obtido pela triangulação das informações a partir das ferramentas de pesquisa utilizadas, no qual o nível de insatisfação quanto à qualidade das vias chegou a $78 \%$ pela escala tipo Likert, resultado semelhante ao encontrado por Sakamoto et al., (2014), que ao estudarem a acessibilidade às propriedades rurais de Itajubá - MG, encontraram que 67,5\% dos entrevistados declararam ter dificuldade de acesso zona urbana e $12 \%$ declararam perder parte da produção devido a essa acessibilidade. 
Quadro 2 - Resultados obtidos a partir da entrevista em grupo focal categoria acesso aos recursos.

\begin{tabular}{|c|c|}
\hline \multicolumn{2}{|r|}{ Categoria: acesso aos recursos } \\
\hline Subcategoria & Principais observações apontadas na entrevista \\
\hline Vias de acesso & $\begin{array}{l}\text { - Péssimas durante a maior parte do ano; } \\
\text { - Pista escorregadia e pontos de atoleiro; } \\
\text { Os carros vivem quebrando e acontecem muitos aciden- } \\
\text { tes, inclusive fatais. }\end{array}$ \\
\hline Eletricidade & $\begin{array}{l}\text { - Acaba facilmente em caso de chuva; } \\
\text { - Dueda de energia frequente; } \\
\text { - Nemora para o restabelecimento de energia; } \\
\text { elétrica; } \\
\text { - Perda de produtos perecíveis. }\end{array}$ \\
\hline Escola infantil & $\begin{array}{ll}\text { - } & \text { Há ônibus escolares para o transporte; } \\
\text { - Não há problemas para o acesso infantil a escola. }\end{array}$ \\
\hline $\begin{array}{l}\text { Área da } \\
\text { propriedade }\end{array}$ & $\begin{array}{l}\text { - Tamanho médio das propriedades no assentamento é de } \\
25 \text { ha; } \\
\text { - Acreditam que está bom para desenvolver as atividades; } \\
\text { - Comentaram sobre uma prática comum no assentamento, } \\
\text { arrendamento de terras, aproximadamente } 15 \text { mil reais por } \\
\text { ano para } 20 \text { ha arrendados. }\end{array}$ \\
\hline Água & $\begin{array}{l}\text { - O assentamento possui poços artesianos para o } \\
\text { abastecimento; } \\
\text { - Não há falta para usos domésticos; } \\
\text { - As represas do assentamento conseguem se manter } \\
\text { abastecidas mesmo durante a época da seca e assim, suprir } \\
\text { a dessedentação dos gados. } \\
\text { - No entanto, a associação pede para não se utilizar essa } \\
\text { água em atividades de irrigação. }\end{array}$ \\
\hline $\begin{array}{l}\text { Máquinas agrí- } \\
\text { colas }\end{array}$ & $\begin{array}{l}\text { - A associação do assentamento possui um trator para uso } \\
\text { dos moradores; } \\
\text { - Há muitas quebras, mas a associação arca com os custos; } \\
\text { - Só há fila de espera nas épocas de gradagem e renovação } \\
\text { do pasto; } \\
\text { - Atualmente as pessoas do assentamento estão utilizando } \\
\text { roçadeiras costais em detrimento da capina. }\end{array}$ \\
\hline Financiamento & $\begin{array}{l}\text { - Conseguir um avalista com casa foi citada com uma das } \\
\text { principais dificuldades; } \\
\text { Dificuldade em conseguir as garantias que os bancos } \\
\text { exigem. }\end{array}$ \\
\hline
\end{tabular}

Fonte: Pesquisa de Campo.
Cabral, Vital e Menelau (2013) ao estudarem a distribuição da produção de assentamentos localizados no município de Moreno, interior do estado de Pernambuco, encontraram que $100 \%$ dos entrevistados declararam a precariedade das vias como a maior dificuldade para o escoamento da produção. Sendo assim, segundo esses autores, esse cenário pode inviabilizar a própria continuidade das atividades, visto que os custos envolvidos na distribuição aumentam os preços desses produtos, o que pode fazê-los perder competitividade com produtos oriundos de outras regiões.

No dia seguinte a uma das visitas, o carro da professora (Figura 01) responsável por ministrar as aulas no assentamento ficou atolado na principal via de acesso MT - 458 "Estrada dos Viola". No entanto, verificou-se nas semanas que procederam, tratores da empresa responsável pela manutenção das estradas rurais trabalhando nas vias do assentamento, o que melhorou em muito a qualidade delas como pôde ser observado durante as visitas seguintes, essas que foram feitas por mais de uma opção de via de acesso.

Vale destacar que a qualidade das vias fica mais prejudicada no período das chuvas, que para o local, ocorre aproximadamente de outubro a abril, mesmo cenário apresentado por Oliveira (2016) em estudos num assentamento rural ocalizado no município de Dom Aquino, MT.

Figura 01 - Atolamento na "Estrada dos Viola" (MT - 458).

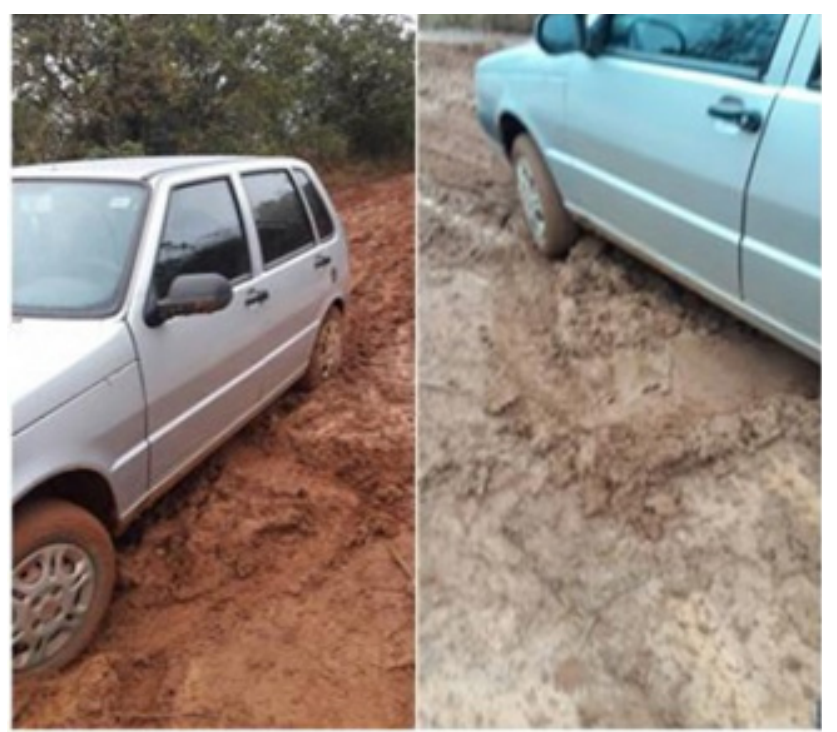

Fonte: Rondonópolis, MT, 2017. 
Esse cenário pode locasionar perdas na quantidade e qualidade da produção destinada à comercialização na cidade, gerar prejuízos aos veículos dos assentados, dificultar o acesso de atravessadores ao assentamento e o deslocamento dos assentados ao centro da cidade para resolução de problemas pessoais, assim como, perda de vidas, como foi citado na entrevista em grupo focal.

Ainda quanto ao acesso aos recursos, o fornecimento de energia elétrica se mostrou um ponto que poderia ser melhorado em programas de desenvolvimento rural e poderia vir a contribuir com a soberania alimentar, pois como relatado pelos alunos-assentados, durante a época de chuva a queda de energia elétrica nas propriedades é frequente e o tempo para o restabelecimento da energia em muitas ocasiões leva dias para ser solucionado, nesses casos, aqueles que trabalham com produtos perecíveis, como derivados de leite, por exemplo, acabam por perder seus produtos. Importante destacar (Quadro 2) que nenhum dos alunos possui em sua residência uma fonte de energia elétrica alternativa.

Quanto à educação infantil, há transporte escolar para as crianças e segundo os estudantes esse não é um problema no assentamento. Este acesso à educação infantil, além de seu serviço de formação escolar, pode contribuir com o desenvolvimento local das famílias visto que em muitas escolas as crianças desenvolvem projetos multidisciplinares, como por exemplo, hortas escolares com base agroecológica, assim como a existente na EMREF Padre Dionísio Kuduavizcz, onde elas aprendem técnicas que podem ser transferidas para seu cotidiano e a valorizar os recursos locais disponíveis. Merçon et al., (2012) a partir de hortas, trabalharam na construção de um cenário de educação integrada por meio da agroecologia, visto que essa ciência abrange diferentes dimensões (agrária, ambiental, econômica e social), a qual permite a realização de práticas que promovam pelo menos seis integrações: teoria e prática; disciplinas e saberes; epistemologia, política e ética; atores e setores; regional e global e presente, passado e futuro.

O acesso à água não é um problema para os moradores do assentamento, visto que o assentamento conta com dois poços artesianos para a captação e rede de distribuição para o fornecimento de água para os lotes. Quanto a disponibilidade de água para uso em suas atividades agrícolas, segundo os entrevistados, a associação recomenda não utilizar a água oriunda dos poços para a irrigação. No entanto, devido à alta pluviosidade durante o período das águas e a textura do solo, segundo os moradores, bastante argilosa, as represas existentes nas propriedades, conseguem manter-se abastecidas durante o decorrer do ano, e assim, garantir a dessedentação dos animais, a pesca de peixes não comerciais e a piscicultura, contribuindo assim para o fornecimento de alimentos e complemento de renda para a família. Essa realidade não é a mesma de outro assentamento localizado nas proximidades, como apresenta Assunção et al., (2012) em seus estudos no Assentamento Fazenda Esperança, Rondonópolis - MT, os pesquisadores apontaram a escassez de água como o maior problema do assentamento, sendo ela um dos principais fatores que influenciam na venda dos lotes.

Quanto ao tamanho das propriedades, que segundo os alunos possuem em média 25 hectares, existiu certa divergência nas respostas do grupo, conforme a técnica de diagnóstico aplicada, o que é normal segundo autores de consagrados manuais para trabalhos de pesquisa participativa como Geilfus (2002) e Verdejo (2006), por isso, segundo esses autores é importante à triangulação de informações. Sendo assim, neste trabalho, por meio da ferramenta de entrevista em grupos focais os estudantes relataram que o tamanho das propriedades satisfaz suas necessidades, onde é possível desenvolver suas atividades e ainda, em alguns casos, há moradores que optam por arrendarem parte de seus lotes, no qual, arrendam-se 20 ha por um valor de 15 mil reais anuais, prática que pode estar ocorrendo devido ao envelhecimento das famílias, o que limita a mão de obra familiar disponível para a exploração da propriedade (OLIVEIRA; RODRIGUES, 2010). No entanto, ao se analisar a satisfação em relação ao tamanho da propriedade, por meio da escala tipo Likert, essa resposta não foi unânime, como pode ser observado na tabela 1, a qual traz 33,3\% (respostas em desacordo), $22,2 \%$ (indiferentes) e 44,4\% (em acordo), essa diferença pode ter sido em função da participação de alunos diferentes nos dias de aplicação das metodologias, visto que as práticas ocorreram em dias distintos, ou ainda, um desconforto do(s) participantes em manifestarem sua real opinião na entrevista em grupo focal.

No caso das máquinas agrícolas, segundo os alunos, a associação dos moradores conta com um trator, o qual ela mesma arca com os gastos em manutenção. Segundo os entrevistados a procura pelo uso da máquina é maior nos períodos de renovação de pastagem e operação de gradeamento do solo. Os resultados apontados pela escala tipo Likert apresentaram-se bem distribuídos quanto à concordância em relação ao acesso das máquinas agrícolas da associação, o que por sua vez dificulta a compreensão desse tema, mais uma vez, a triangulação das informações foi importante para avaliar o cenário. A importância do trator para os assentados se faz 
principalmente pelo rendimento operacional da máquina ser muito superior ao rendimento do trabalho manual, além desses trabalhos despenderem muita energia, tempo e mão de obra, quando executados manualmente.

Outro fator importante relatado pelos estudantes é o uso de roçadeiras costais, que atualmente é uma prática muito utilizada pelas pessoas do assentamento, logo contribui muito para um melhor aproveitamento do tempo nas atividades, visto que o rendimento operacional para a roçada manual encontra-se em torno de $0,092(\mathrm{ha} / \mathrm{H} / \mathrm{dia})$, enquanto o rendimento operacional para a roçada semimecanizada é de aproximadamente 0,15 (ha/H/dia), ou seja, a operação com roçadeira costal apresenta uma eficiência no tempo de trabalho em torno de $40 \%$ superior a roçada manual (SOUZA ; VIEIRA, s.d). Por conseguinte, além de um menor desgaste físico, o trabalhador pode destinar essa diferença de tempo para a realização de outras atividades.

Quanto ao acesso aos financiamentos agrícolas, as principais respostas obtidas via entrevista em grupo focal foram quanto às dificuldades para se cumprir as exigências do banco. Pela escala tipo Likert, $62,5 \%$ das repostas foram de discordância quanto ao atual acesso as linhas de crédito agrícola. Verges (2011) estudando programas de crédito rural em assentamentos do Pontal do Paranapanema - SP destacou a importância dos programas de financiamento rural voltados para os pequenos produtores, os quais, no entanto, na prática não tem conseguido atingir seus objetivos. A autora cita ainda, que os assentados encontram muitas dificuldades para ter acesso a esses créditos, principalmente em dar as garantias que os bancos exigem; mesmo cenário apresentado nos relatos dos moradores do Assentamento PA São Francisco. Oliveira et al., (2016) estudaram o uso de créditos por agricultores familiares do município de Três Fronteiras - SP e constaram a importância desses créditos para a agricultura familiar local, onde $60 \%$ dos entrevistados se beneficiavam da linha de crédito há mais de nove anos, $90 \%$ declararam satisfeitos com a utilização da linha de crédito e 95\% afirmaram que tinham a intensão de continuar a utilizar e usufruir dos benefícios proporcionados que essa linha oferece. No entanto, quanto à facilidade de acesso ao crédito, mais de $60 \%$ declararam ter dificuldades em entregar a documentação exigida pelos bancos.

\section{Modelos DE PRODUÇÃo}

Ao analisar a categoria modelos de produção, percebeu-se ao decorrer das atividades, que a agricultura não é a principal atividade econômica das propriedades, contudo a exploração dos quintais é uma importante fonte de alimentos de origem vegetal para a família, principalmente os pomares, como pôde ser confirmado na visita in loco à propriedade do estudante $\mathrm{Sr}$. A. Esse senhor possui em seu quintal uma grande variedade de plantas alimentícias arbóreas e herbáceas, dentre elas algumas típicas de sua região de origem (Paraíba), como o umbu, esse último utilizado para o preparo da umbuzada, receita muito apreciada pelos proprietários. Ainda quanto a visita a propriedade do Sr. A, constatou-se a produção de uma variedade de feijão bastante tradicional entre agricultores familiares, o feijão-catador. Segundo Sr. A e sua esposa, também participante das aulas de EJA, Sra. B, a produção supre as necessidades do casal, o qual colhe vagens ainda verdes e as utilizam como ingrediente em farofa e cozido no preparo tradicional. De acordo com o casal, essa variedade possui as vantagens de não precisar de cozimento sob pressão e menos tempo de fogo. Sr. A conta também com a criação de gados, galinhas soltas pelo quintal e peixes.

Ao tomar como exemplo a propriedade do Sr. A, percebe-se que a produção da propriedade contribui ativamente para a autônima da família, conforme explicou o próprio casal. Neste sentido, vale destacar a importân cia do autoconsumo para os estabelecimentos rurais brasileiros, no qual a partir do censo agropecuário de 2006, verificou-se que o autoconsumo correspondeu a mais de $50 \%$ da produção total em cerca de $30 \%$ das propriedades, e mais de $90 \%$ da produção total em $18 \%$ delas (GRISA et al., 2014). A partir de estudos no Assentamento Zumbi dos Palmares, no município de Dom Aquino - MT, Oliveira (2016) encontrou em seus estudos que a produção voltada para o autoconsumo é uma importante atividade para as famílias do assentamento, no qual os quintais próximos às casas apresentam uma grande diversidade de frutas, nativas ou exóticas.

Essas unidades familiares, diferentemente de empresas, onde a produção visa à obtenção de lucro, organizam sua produção para garantir o bemestar da família (GRISA et al., 2014). Nesse sentido, além da produção de alimentos a propriedade fornece emprego, lazer e serviços ambientais, visto que possuem uma exploração bastante diversificada com muitas plantas que abrigam e alimentam a fauna e proporcionam uma boa cobertura para o solo.

Ainda quanto à produção de alimentos nas propriedades, além dos problemas apresentados no quadro 3 quanto à produção de hortaliças para comercialização, pode-se contextualizar a falta de tradição nesse tipo de exploração e pouca mão de obra disponível, visto que essa atividade exige um manejo mais intensivo, principalmente quanto aos tratos culturais. Sendo 
assim, segundo os alunos, a produção de hortaliças ocorre em pequenas dimensões, como exemplo, em minicanteiros, recipientes como baldes, dentre outros, localizados próximos às residências, de modo a oferecer uma pequena contribuição à alimentação dos assentados. Quanto à produção animal, tipo de exploração mais tradicional no assentamento, segundo os alunos, atividade amplamente disseminada, seja na criação de gado, ou peixe, ou galinha ou suínos. Essa produção, diferentemente das outras, contribui com a entrega de alimentos a cidade, pois há excedentes de produtos além do autoconsumo da família, dessa forma, são atividades geradoras de recursos financeiros para as famílias.

Quanto a não permanência dos jovens nas propriedades, essa situação pode comprometer a exploração do lote, por conseguinte, a própria autonomia na produção para o mercado e autoconsumo da família. No qual, além da perda quantitativa da mão de obra familiar, tem-se também a perda do próprio vigor físico dos trabalhadores. Esse quadro de envelhecimento da população ainda poderá se agravar, pois segundo projeções do IBGE, a população com idade superior a 65 anos será o dobro da atual em 2024, alcançando até $20 \%$ da população brasileira, o que também poderá ser refletido nos assentamentos (OLIVEIRA; RODRIGUES, 2010). Nesse sentido, seriam interessantes pesquisas exploratórias, a partir de diálogos com os jovens, para que se aprofundasse nesse tema e se entendesse os motivos dessa não permanência dos jovens no assentamento.

Durante uma atividade realizada em sala de aula, a qual objetivou diagnosticar as plantas presentes nos quintais e os saberes dos alunos a respeito delas, mais de 45 plantas foram citadas, dentre elas, plantas de espécies nativas que aparecem espontaneamente, como o bacuri, plantas exóticas que crescem sem necessidade de ser plantada como a jaca e o mamão, e plantas exóticas introduzidas por mudas ou sementes, como o umbu e o cupuaçu. Dentre outros benefícios, essa atividade serviu para valorizar e compartilhar o conhecimento de cada indivíduo e mostrar a grande diversidade de alimentos de origem vegetal nas propriedades, onde a maioria, segundo eles, não necessita de tratos culturais e muitos crescem espontaneamente, sendo necessário apenas colhê-los na planta ou coletá-los no chão, cenário esse favorável à soberania alimentar. Visto que além de possuírem acesso a uma alimentação diversificada, consomem alimentos tradicionais e não dependem de recursos externos para a produção. Realidade contrária aos tradicionais programas governamentais de combate a fome na região do semiárido, onde, além de estimularem o consumo de alimentos que não são passiveis de serem produzidos no local, contribuem para a perda do saber tradicional referente às plantas locais (GAMARRA-ROJAS et al., 2004). Para ressaltar a importância de programas de desenvolvimento rural baseado em promoção da flora local, chama-se atenção para o beneficiamento do baru (Figura 02) realizado por um produtor assentado em um assentamento limítrofe ao Assentamento PA São Francisco, o qual comercializa o $\mathrm{kg}$ da farinha e da castanha torrada a $\mathrm{R} \$ 60,00$ (preço praticado durante o período de visitas ao assentamento, $1^{\circ}$ semestre de 2017). Ainda segundo os estudantes, esse produtor precisa comprar baru em outras áreas, pois a oferta local não está atendendo sua demanda.

Figura 02 - Castanha de baru torrada produzida em assentamento rural, Rondonópolis, MT, 2017.

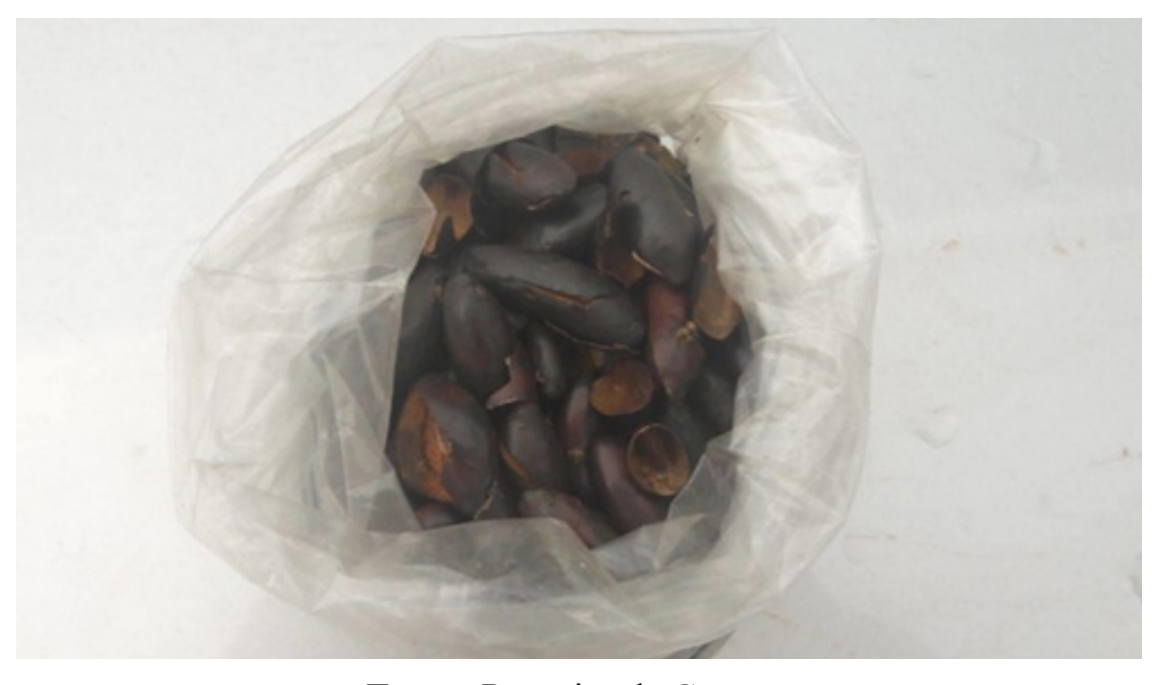

Fonte: Pesquisa de Campo.

Em relação ao uso de agrotóxicos, a escala tipo Likert apresentou que $78 \%$ dos entrevistados discordam em utilizar esses produtos, no entanto, utilizam desse meio, pois, segundo eles, é o método que apresenta resultado mais eficaz. Também se percebeu que os produtores não costumam utilizar equipamentos de proteção individual (EPI's) nas aplicações, quando muito, utilizam apenas a máscara, também não costumam lavar as roupas utilizadas nas aplicações separadas das roupas comuns. Os entrevistados ainda relataram que é comum sentir alguns sintomas após as aplicações, dos quais se destacam a coceira pelo corpo, tontura, dores de cabeça e 
Quadro 3 - Resultados obtidos a partir da entrevista em grupo focal categoria modelos de produção.

\begin{tabular}{|c|c|}
\hline \multicolumn{2}{|r|}{ Categoria: modelos de produção } \\
\hline Subcategoria & Principais observações apontadas na entrevista \\
\hline $\begin{array}{l}\text { Jovens trabalhando na } \\
\text { propriedade }\end{array}$ & $\begin{array}{l}\text { - Não há mais jovens trabalhando nas propriedades; } \\
\text { - Os jovens não estão ficando no assentamento; } \\
\text { - Faltam atrativos para os jovens permanecerem no } \\
\text { assentamento. }\end{array}$ \\
\hline $\begin{array}{c}\text { Contratação de trabalha- } \\
\text { dores }\end{array}$ & $\begin{array}{l}\text { - Mutirões e trocas de s } \nabla \text { rviço não têm funcionado } \\
\text { no assentamento, as pessoas não aparecem; } \\
\text { - Quanto à vacinação do gado, não está fácil encon- } \\
\text { trar trabalhadores, quando se encontra, cobram } \\
\text { valores muito altos. }\end{array}$ \\
\hline Pomares e hortas & $\begin{array}{l}\text { - Hortaliças: não se consegue manter uma horta por } \\
\text { causa da falta de água para irrigação, consegue-se } \\
\text { apenas manter hortas próximas à residência para } \\
\text { alimentação da família; } \\
\text { - Ataque de insetos e doenças dificultam as ativi- } \\
\text { dades; } \\
\text { - Pomares: contribuem bastante para alimentação } \\
\text { da família. }\end{array}$ \\
\hline Plantas tradicionais & $\begin{array}{l}\text { - Caruru e serralha aparecem espontaneamente na } \\
\text { propriedade, antigamente se comia, mas hoje não } \\
\text { se consome mais; } \\
\text { - Há um homem vizinho ao assentamento que fa- } \\
\text { brica farinha e outros produtos de baru para co- } \\
\text { mercialização; } \\
\text { - Antigamente haviam muitos pés de melão-croá } \\
\text { no assentamento, hoje não se encontra mais, mui- } \\
\text { to difícil. }\end{array}$ \\
\hline Peixes & $\begin{array}{l}\text { - Atividade não está compensando, pois, o preço da } \\
\text { ração está muito alto; } \\
\text { - Roubos de peixes à noite (ocasionalmente); } \\
\text { - Atualmente a criação de peixes ocorre mais para } \\
\text { o próprio consumo sejam nativos ou introduzidos, } \\
\text { alguns utilizam alimentação artificial, porém em } \\
\text { menor quantidade. }\end{array}$ \\
\hline
\end{tabular}

Quadro 3 - Resultados obtidos a partir da entrevista em grupo focal categoria modelos de produção. (Cont.)

\begin{tabular}{|c|c|}
\hline Gados, suínos e aves & $\begin{array}{l}\text { - Criam para o próprio consumo e vendem a produ- } \\
\text { ção excedente; } \\
\text { - Comentaram que essas atividades são amplamen- } \\
\text { te desenvolvidas no assentamento. }\end{array}$ \\
\hline Agrotóxicos & $\begin{array}{l}\text { - Comentaram que é comum sentirem coceira pelo } \\
\text { corpo na hora da aplicação, assim como, tontura, } \\
\text { dores de cabeça e outros sintomas; } \\
\text { - Não é comum utilizar EPI's durante a aplicação, } \\
\text { às vezes utilizam a máscara; } \\
\text { - A maioria não separa as roupas utilizadas durante } \\
\text { a aplicação de agrotóxicos das roupas comuns na } \\
\text { hora da lavagem; } \\
\text { - Segundo eles, a maioria das pessoas não respei- } \\
\text { ta a carência dos agrotóxicos, mesmo quanto ao } \\
\text { consumo de leite. }\end{array}$ \\
\hline Defensivos naturais & $\begin{array}{l}\text { - Comentaram sobre o fumo, mas segundo eles } \\
\text { para ser eficiente tem que passar frequentemente; } \\
\text { - Mostraram algum conhecimento sobre o preparo } \\
\text { de outras receitas à base de álcool, detergente e } \\
\text { pimenta; } \\
\text { - Um senhor comentou que "para combater lagarta } \\
\text { é veneno bravo mesmo". }\end{array}$ \\
\hline
\end{tabular}

outros sintomas. Santana et al. (2016) encontraram realidade parecida ao estudar trabalhadores rurais do município de Picos - PI, onde 94,1\% dos entrevistados afirmaram considerar os agrotóxicos como prejudiciais à saúde, contudo 56,8\% afirmaram não fazer uso de EPI's durante as aplicações. Outro levantamento feito pelos pesquisadores foi quanto aos sintomas de envenenamento por agrotóxicos, de modo que $15 \%$ dos entrevistados afirmaram já ter sentido algum tipo de sintoma, onde para esse grupo de pessoas (15\%), os sintomas citados foram: dores de cabeça $(33,4 \%)$, enjoo (25\%), vertigem/tontura (16,6\%), irritação de pele $(12,6 \%)$ e perda de apetite (4,2\%). Castro et al., (2011), em estudos com assentados da reforma agrária no município de Russas - $\mathrm{CE}$, encontraram nos relatos dos entrevistados os seguintes sintomas: vertigens/tonturas, alergia na pele/ coceira e mal-estar generalizado, como respostas dentre os $23,3 \%$ dos

v.21, n.2,2018 444444 Retratos De Assentamentos $\longmapsto \gg \gg \triangleright$ 
agricultores que declararam fazer uso de agrotóxicos. Souza et al., (2013), pesquisando o impacto dos agrotóxicos na saúde de assentados em Jardim Alegre-PR, trazem em seu trabalho que $75 \%$ dos entrevistados sentem algum sinal de sintoma de intoxicação, durante ou após a aplicação de agrotóxicos, dentre os sintomas, os mais comuns nas respostas foram: problemas estomacais $(16,7 \%)$, dor de cabeça $(14,2)$ e boca seca $(13,3)$. Como se pôde observar nesses estudos, os sintomas foram muito parecidos com os relatados pelos estudantes do EJA do Assentamento PA São Francisco, conforme apresentado no quadro 3. Porto e Soares (2012) colocam esses relatos de experiências vividas por trabalhadores rurais e outras pessoas expostas aos agrotóxicos no meio rural, como importante elemento de pesquisa, o qual pode contribuir para um melhor entendimento da problemática e auxiliar na construção de políticas públicas voltadas para o tema. Interessante colocar na discussão os estudos de Mansur e D'Angioli (2013) quanto à produtividade com ou sem uso de agrotóxicos. Eles analisaram a percepção de agricultores assentados de Araras - SP, aonde os pesquisadores chegaram à conclusão de que não houve perda de produtividade pelo não emprego de agrotóxicos na agricultura quando comparada aos produtores que utilizam esses produtos.

\section{TransformaÇÃo E COMERCIALIZAÇÃo}

Ao analisar o indicador associação dos moradores pela escala tipo Likert, $62,5 \%$ dos entrevistados discordaram da atual conduta da associação. Por meio da entrevista em grupos focais, os principais apontamentos feitos pelos entrevistados foram quanto à mensalidade, pequeno número de sócios e época de maior número de associados à procura de utilizar o trator disponível pela associação. Silva e Barone (2011) atribuem a baixa adesão dos moradores às associações a premissa de que "nossa" sociedade não tem como cultura o trabalho coletivo; esta concepção pôde ser percebida pelos comentários dos próprios estudantes conforme apresentou o Quadro 4, onde segundo eles os trabalhos coletivos e trocas de favores não têm funcionado no assentamento, "as pessoas não aparecem".

O associativismo rural se apresenta como uma importante estratégia para garantir aos assentados a permanência na terra, o qual pode proporcionar maior autonomia dos agricultores, beneficiar o relacionamento com o mercado e sociedade local e facilitar os processos de produção (SILVA e BARONE, 2011). Dessa forma, considerando-se a importância desse esquema de organização para os assentados, recomendam-se novos estudos que permitam aprofundar nesse tema e entender melhor o motivo dessa
Quadro 4 - Resultados obtidos a partir da entrevista em grupo focal categoria transformação e comercialização.

\begin{tabular}{|c|c|}
\hline \multicolumn{2}{|r|}{ Categoria: transformação e comercialização } \\
\hline Subcategoria & Principais observações apontadas na entrevista \\
\hline $\begin{array}{l}\text { Associação do } \\
\text { assentamento }\end{array}$ & $\begin{array}{l}\text { - Há uma associação no assentamento, } \\
\text { mensalidade } 10 \text { reais, no entanto há poucas } \\
\text { pessoas associadas; } \\
\text { - As pessoas só frequentam a associação na } \\
\text { época de renovação de pastagem (gradagem), } \\
\text { pois assim pegam desconto no aluguel de } \\
\text { máquinas. }\end{array}$ \\
\hline $\begin{array}{l}\text { Transformações, } \\
\text { artesanatos, } \\
\text { atravessadores e } \\
\text { feiras-livres }\end{array}$ & $\begin{array}{l}\text { - Dentre os participantes não há pessoas que } \\
\text { comercializam os produtos em feira ou } \\
\text { mercados da cidade, no entanto comentaram } \\
\text { que há alguns assentados que fazem essa } \\
\text { comercialização; } \\
\text { - As vendas mais comuns são: comercialização } \\
\text { nas proximidades do assentamento (entrega } \\
\text { de casa em casa) e na própria propriedade; } \\
\text { - O assentamento é visitado por atravessadores } \\
\text { que buscamprodutosaliparacomercializarem } \\
\text { nas feiras livres; } \\
\text { - Há duas senhoras assentadas que produzem } \\
\text { farinha de mandioca de modo artesanal; } \\
\text { - Segundo uma participante "uma mulher } \\
\text { tem uma produção bem diversificada, } \\
\text { melancia, farinha e milho ela vende aqui no } \\
\text { assentamento"; } \\
\text { Muitos entregam leite a um produtor de } \\
\text { muçarela; } \\
\text { Uma das participantes utiliza leite de nelore } \\
\text { para a produção de queijo. }\end{array}$ \\
\hline $\begin{array}{l}\text { Localização geográfi- } \\
\text { ca do assentamento }\end{array}$ & $\begin{array}{l}\text { - Acreditam que o assentamento esteja bem } \\
\text { localizado. }\end{array}$ \\
\hline
\end{tabular}

Fonte: Pesquisa de Campo. 
alta discordância em relação à conduta da associação e a baixa adesão dos assentados.

Ao se analisar os canais de comercialização, verificou-se que poucos produtores levam seus produtos para venda em feiras livres e mercados localizados no perímetro urbano; geralmente os produtores comercializam seus produtos em sua propriedade ou de porta em porta no próprio assentamento e assentamentos próximos. Esses canais são conhecidos como circuito ou canal curto de comercialização, termo que reforça a proximidade geográfica e a relação produtor/consumidor. Geralmente, as propriedades que trabalham com canais curtos de comercialização possuem produção mais diversificada com alta variedade de produtos vegetais e animais (DAROLT et al., 2013). Em pesquisa que teve como objetivo caracterizar a comercialização dos produtos da agricultura familiar de Tangará da SerraMT, Martins et al., (2012) entrevistaram 125 produtores e encontraram que $35 \%$ deles comercializam seus produtos diretamente nas feiras-livres, $25 \%$ em supermercados, $1 \%$ em escolas e $39 \%$ (vendas diretas na propriedade, outras cidades e entrega à domicilio). Ainda segundo os autores, esses canais permitem aos produtores acessar o mercado com maior facilidade devido a menor burocracia, de modo que essa tem sido a principal fonte de renda da grande maioria dos entrevistados. Vasconcelos et al., (2016) estudando sete assentamentos rurais da microrregião de Rondonópolis encontraram os seguintes destinos: prefeitura municipal (merenda escolar) $80 \%$, redes de supermercados e feiras-livres $10 \%$, esse estudo indica uma realidade bastante diferente da encontrada no Assentamento Rural PA São Francisco.

Outra prática comum no Assentamento PA São Francisco é a venda para atravessadores que saem de outros locais para buscarem produtos nesse assentamento. No entanto, percebeu-se que os atravessadores são na verdade intermediadores, em alguns casos, outros assentados, como exemplo, um dos alunos do EJA. Essa distinção é feita, visto que esses intermediadores não repassam os produtos comprados a outros comerciantes, mas o comercializam diretamente com os consumidores em feiras, domicílios, etc. Essa relação propicia maior poder ao produtor na hora de comercializar seus produtos, pois em muitos casos esses intermediadores são pessoas próximas aos produtores como, familiares, amigos e conhecidos (UENO et al., 2016). Pela escala tipo Likert, o indicador canais de comercialização (feira e atravessador) teve índice de $62,5 \%$ de aprovação pelos alunos.

Quanto à transformação dos produtos, dentre os estudantes, verificouse a existência de uma aluna que produz queijos para comercialização, a existência de mais duas senhoras no assentamento que produzem farinha de mandioca de modo artesanal, além de um morador de um assentamento vizinho que beneficia o baru para comercialização de farinha e castanha torrada. Essas transformações possuem grande importância às unidades de exploração familiar de pequeno porte, visto que podem agregar valor aos produtos (DAROLT et al., 2013). Vasconcelos et al., (2016), a partir de um estudo que buscou caracterizar as atividades agroindustriais em assentamentos da microrregião de Rondonópolis - MT, encontraram que aqueles produtores que trabalhavam com o processamento de produtos conseguiam aumentar sua renda em $30-50 \%$. Dentre esses produtos processados, esses pesquisadores destacam: a farinha de mandioca $(28,6 \%)$, o leite pasteurizado $(26,6)$, o abatedouro de frangos $(28,6 \%)$ e o despolpamento de frutos $(14,6 \%)$. Silva (2015), caracterizando o processamento artesanal de produtos em assentamentos rurais de Ilha Solteira - SP, encontrou que o processamento de queijo fresco incrementa em média R \$ 270,00 mensais a mais na renda dos produtores quando comparado a comercialização do litro de leite fresco.

Para análise da localização do assentamento, faz-se necessário primeiramente, esclarecer que a discussão girou em torno de sua localização geográfica no espaço, ou melhor, compreendido pelos estudantes, a posição do assentamento em relação às vias de acesso e distância do centro da cidade, dessa forma, não se discutiu tipos de solo, relevo, vegetação, dentre outros. Sendo assim, por meio da entrevista em grupos focais as respostas foram unânimes entre os participantes quanto à boa localização do assentamento. Nesse sentido, Ramiro (2008) traz a importância da localização (distância dos centros de comercialização) como uma das premissas que podem garantir a continuação das atividades de modo sustentável a médio e longo prazo em projetos de implantação de novos assentamentos.

\section{Políticas Agrícolas}

Segundo os dados obtidos na entrevista em grupo focal, os agricultores nunca foram convidados a participar do desenvolvimento de políticas públicas voltadas para seu assentamento.Para Milani (2008) a participação social parte do pressuposto que todos devem estar cientes das regras a que serão submetidos, assim como, influenciar em diferentes níveis para a elaboração dessas regras. Ainda nesse sentido, "a participação social deriva de uma concepção de cidadania ativa. Ou seja, através da participação é possível construir a cidadania e fortalecer os direitos sociais" (CUNHA, 2010, p. 53). "A importância da participação está no seu caráter educativo, libertador, 
Quadro 5- Resultados obtidos a partir da entrevista em grupo focal categoria políticas agrícolas.

\begin{tabular}{|c|c|}
\hline \multicolumn{2}{|c|}{ Categoria: políticas agrárias } \\
\hline Subcategoria & $\begin{array}{c}\text { Principais observações apontadas } \\
\text { na entrevista }\end{array}$ \\
\hline \multirow{2}{*}{$\begin{array}{c}\text { Participação em políticas } \\
\text { e planos de desenvolvi- } \\
\text { mento }\end{array}$} & $\begin{array}{l}\text { Nunca foram convidados para debaterem propos- } \\
\text { tas de melhorias no assentamento; } \\
\end{array}$ \\
$\begin{array}{l}\text { Comentaram sobre um projeto de piscicultura que } \\
\text { a Secretária da Agricultura do município estava } \\
\text { desenvolvendo, no entanto, segundo os entrevis- } \\
\text { tados, o projeto se limitava a construção de tan- } \\
\text { ques e muitas vezes não se respeitava a indicação } \\
\text { do proprietário para o local de escavação da re- } \\
\text { presa, resultando em alguns casos de "represas" } \\
\text { que nunca ficaram cheias de água. }\end{array}$ \\
\hline
\end{tabular}

Fonte: Pesquisa de Campo.

pois modifica o comportamento individualista das pessoas, elimina a postura receptiva do assistencialismo e paternalismo estatal, estimula a união e o coletivismo" (PEREIRA e PEIXOTO, 2004, p. 14). Em estudos com assentados do Movimento Sem Terra e sua participação no Sistema Único de Saúde, Cunha (2010) mostrou que apesar do desconhecimento do tema, os assentados mostraram-se muito dispostos a aprender e compreender sobre as informações que poderiam ajudá-los a atuar junto com o Conselho Municipal de Saúde para contribuir beneficamente em uma mudança de suas realidades.

\section{CONSIDERAÇões FINAIS}

Percebeu-se que a agricultura não é a principal atividade das pessoas ali residentes, acredita-se que a falta de mão de obra e o envelhecimento da população sejam os maiores empecilhos para essa atividade. Acredita-se que os frutos nativos possuem um grande potencial para colaborar com a alimentação e renda da família, visto que o local conta com uma grande variedade de frutos adaptados as condições locais, os quais por sua vez, poderiam auxiliar nas principais dificuldades apontadas pelo diagnóstico, ou seja, falta de mão de obra, irrigação e intoxicações por agrotóxicos

Quanto a soberania alimentar, apesar da deficiência em alguns serviços, os assentados ainda sim, possuem uma ampla fonte de alimentos; possuem acesso aos alimentos e aos recursos disponíveis para sua produção. No entanto, há indícios de que essa situação possa não ser transmitida para as próximas gerações, visto que os jovens não estão permanecendo no assentamento e, devido ao envelhecimento, falta de mão de obra e assistência técnica, essas pessoas estão preferindo arrendar grande parte de suas propriedades e viver com aquilo que se pode manusear próximo as suas casas.

\section{REFERÊNCIAS}

ASSUNÇÃO, H. H. T.; OLIVEIRA, I. L.; BARBOSA, R. C.; STURZA, J. A. I. A segurança e soberania alimentar: contribuição ao debate a partir de estudo no Assentamento Fazenda Esperança em Rondonópolis - MT. In: Encontro Nacional de Geografia Agrária, 21., 2012, Uberlândia - MG. Anais eletrônicos... Uberlândia-MG: UFU, 2012. Disponível em: $<$ http:// www.lagea.ig.ufu.br/xx1enga/anais_enga_2012/eixos/1165_1.pdf $>$. Acesso em: 08 mar. 2017.

CABRAL, S.; VITAL, T.; MENELAU, A. S. Logística de distribuição da produção dos assentamentos Timbó e Granja Jumbo em Moreno, Estado de Pernambuco. Informações Econômicas, São Paulo, v. 43, n. 2, p. $57-$ 67, mar.-abrl., 2013. Disponível em: <http://www.iea.sp.gov.br/ftpiea/ publicacoes/ie/2013/tec5-0413.pdf>. Acesso em: 08 jul. 2017.

CARDOSO, J. C. Presentación. In: FAO. Organização das Nações Unidas para Alimentação e Agricultura. Ley Marco "Derecho a la alimentación, seguridade y soberania alimentaria". FAO, 2013. Disponível em: $<$ http:// www.fao.org/3/a-au351s.pdf $>$. Acesso em: 08 jul. 2017.

CARVALHO, N. M.; NAKAGAWA, J. Sementes: ciência, tecnologia e produção. $4^{\circ}$ ed. Jaboticabal - SP: Funep, 2000. p. 7-8.

CASTRO, M. G. G. M. ; FERREIRA, A. P. ; MATTOS, I. E. Uso de agrotóxicos em assentamentos de reforma agrária no município de Russas (Ceará, Brasil): um estudo de caso. Epidemiologia e Serviço de Saúde, 
Brasília, v. 20, n. 2, p. 245-254, 2011. Disponível em: <http://scielo.iec.gov. br/pdf/ess/v20n2/v20n2a13.pdf > . Acesso em: 01 ago. 2017.

CUNHA, A. P. Participação social dos trabalhadores rurais assentados do movimento sem terra, no sistema único de saúde. Florianópolis: UFSC, 2010. Originalmente apresentada como dissertação de mestrado, Universidade Federal de Santa Catarina. Disponível em: <https:// repositorio.ufsc.br/xmlui/bitstream/handle/123456789/94029/280698. pdf? sequence=1\&isAllowed=y $>$. Acesso em: 11 ago. 2017 .

DAROLT, M. R.; LAMINE, C.; BRANDEMBURG, A. A diversidade dos circuitos curtos de alimentos ecológicos: ensinamentos do caso brasileiro e francês. Agriculturas, Rio de Janeiro, v. 10, n. 2, p. 8-13, junho, 2013. Disponível em: $<$ http://aspta.org.br/wp-content/uploads/2013/09/RevistaAgriculturas-V10N2-Artigo-1.pdf $>$. Acesso em: 09 ago. 2017.

FAO. Organización de las Naciones Unidas para la Alimentación y la Agricultura. Agicultores pequeños y familiares. 2013. Disponível em: $<$ http://www.fao.org/docrep/018/ar588s/ar588s.pdf >. Acesso em: 06 jul. 2017.

GAMARRA-ROJAS, G.; FREIRE, A. G.; MOREIRA, J. M.; ALMEIDA, P. Frutas nativas: de testemunhos da fome a iguarias na mesa. Revista Agriculturas, Rio de Janeiro, v. 1, n.1, p. 15-18, novembro de 2004. Disponível em: <http://aspta.org.br/wp-content/uploads/2013/04/ Agriculturas_V1N1_NOV2004.pdf $>$. Acesso em: 22 mai. 2017.

GEILFUS, F. 80 herramientas para el desarollo participativo: diagnóstico, planificación, monitoreo, evaluación. San José, C. R.: IICA, 2002. Disponível em: $<$ http://ejoventut.gencat.cat/permalink/aac2bb0c2a0c-11e4-bcfe-005056924a59>. Acesso em: 15 jun. 2017.

GIL, A. C. Métodos e técnicas de pesquisa social. São Paulo: Atlas, 1991.

GRISA, C.; SCHNEIDER, S.; CONTERATO, M. A. O autoconsumo nos estabelecimentos rurais brasileiros: importância e distintas propostas de mensuração. In: CONTERATO, M. A.; RADOMSKY, G. F. W.;
SCHNEIDER, S (Org.). Pesquisa em desenvolvimento rural: aportes teóricos e proposições metodológicas. Porto Alegre: Editora UFRGS, 2014.

MANSUR, A. L.; D'ANGIOLI, A. M.; Análise do uso de agrotóxicos em assentamentos rurais. In: Congreso Latinoamericano de Agroecologia SOCLA, 4., 2013, Lima. Anais eletrônicos... Lima - Peru: Universidad Nacional Agraria La Molina, 2013. Disponível em: <http://orgprints. org/25094/>. Acesso em: 03 ago. 2017.

MARTINS, W. R. M.; COSTA, R. M.; LIMA, A. F. A.; MATTOS, A. L. Estratégias de comercialização dos produtos da agricultura familiar: um estudo de caso na comunidade Vale do Sol II, Tangará da Serra - MT. In: Encontro Nacional de Engenharia de Produção, 32., 2012, Bento Gonçalves - RS. Anais eletrônicos... Bento Gonçalves - RS: Fundação Parque de Eventos, 2012. Disponível em: $<\mathrm{http}: / / w w w . a b e p r o . o r g . b r / b i b l i o t e c a /$ enegep2012_TN_STO_163_952_20350.pdf>. Acesso em: 09 ago. 2017.

MAZOYER, M.; ROUDART, L. História das agriculturas no mundo do neolítico à crise contemporânea. Tradução: Cláudia F. Falluh Balduino Ferreira. São Paulo: Editora UNESP; Brasília, DF: NEAD, 2010.

MERÇON, J.; AGUILAR, M. Á. E.; ARMELLA, M. I. N.; NÚÑEZ, I. I. F.; SÁNCHEZ, A. A.; MÉNDEZ, E. D. G. Cultivando la educación agroecológica. Revista Mexicana de Investigación Educativa, v. 17, n. 55, p. 1201-1224, 2012. Disponível em: <https://www.uv.mx/personal/jmercon/ files/2011/08/Mercon-et-al2012_RMIE.pdf>. Acesso em: 04 jul. 2017.

OLIVEIRA, G. W. ; FERRARI, J. V. F.; MATOSO, A. O. Análise do uso do Pronaf por agricultores familiares no município de Três Fronteiras - SP. In: Simpósio Nacional de Tecnologia em Agronegócio, 8., Jales - SP, 2016. Anais eletrônicos... Jales - SP: Fatec, 2016. Disponível em: $<$ http://www. fatecjales.edu.br/sintagro/images/anais/tematica7/analise-do-uso-do-pronafpor-agricultores-familiares-no-minicipio-de-tres-fronteiras-sp.pdf $>$. Acesso em: 12 ago. 2017.

OLIVEIRA, I. L. A luta "na" terra: pluriatividade e multifuncionalidade como alternativas de permanência no campo aos assentados de Zumbi dos Palmeres - MT. Santa Maria - RS: UFSM, 2016. Originalmente 
apresentada como dissertação de mestrado, Universidade Federal de Santa Maria.

OLIVEIRA, S. M.; RODRIGUES, R.B. Envelhecimento em assentamentos rurais: um olhar sobre a realidade atual. 2010. Disponível em: $<\mathrm{https} / /$ www.uniara.com.br/legado/nupedor/nupedor 2010/00\%20textos/ sessao_5A/05A-10.pdf>. Acesso em: 29 jun. 2017.

ORTEGA-CERDÀ, M.; RIVERA-FERRE, M. G. Indicadores internacionales de Soberania Alimentaria. Nuevas herramientas para una nueva agricultura. Revista Iberoamericana de Economía Ecológica, Morelia, v. 14, p. 5377, 2010. Disponível em: <http://www.raco.cat/index.php/Revibec/article/ viewFile/200507/268011>. Acesso em: 25 nov. 2016.

PENGUE, W. A. Agricultura industrial y transnacionalizacion en America Latina - la transgénises de un continente?. $1^{\circ}$ ed. Buenos Aires: Universidad de Buenos Aires/ Grupo de Ecología del Paisaje y Medio Ambiente, 2005.

PEREIRA, C. C.; PEIXOTO, Marcus. Importância da participação nos métodos de planejamento do desenvolvimento de assentamentos rurais. In: Congresso da Sober, 42., Cuiabá, 2004. Anais eletrônicos... Cuiabá: Sober. Disponível em: $<$ http://www.sober.org.br/palestra/12/110479.pdf $>$. Acesso em: 11 ago. 2017.

PORTO, M. F. ; SOARES, W. L. Modelo de desenvolvimento, agrotóxicos e saúde: um panorama da realidade agrícola brasileira e propostas para uma agenda de pesquisa inovadora. Revista Brasileira de Saúde Ocupacional, São Paulo, v. 37, n. 125, p. 17-50, 2012. Disponível em: <http://www.scielo. br/pdf/rbso/v37n125/a04v37n125.pdf>. Acesso em: 02 ago. 2017.

RAMIRO, P. A. Assentamentos rurais: o campo das sociabilidades em transformação. $O$ caso dos assentados do Novo Pontal. São Carlos - SP: UFSCAR, 2008. Originalmente apresentada como tese de doutorado, Universidade Federal de São Carlos. Disponível em: $<$ http://www.reformaagrariaemdados.org.br/sites/default/files/2008\%20 Patr\%C3\%ADcia\%20Alves\%20Ramiro.pdf $>$.Acesso em: 11 ago. 2017. SAKAMOTO, E.; MACHADO, M. H.; LIMA, J. P. Acessibilidade de agricultores familiares no município de Itajubá - MG: o ponto de vista dos usuários. In: Congresso de Pesquisa e Ensino em Transporte, 28., 2014, Curitiba - PR. Anais eletrônicos... Curitiba - PR: ANPET. Disponível em: <http://www.anpet.org.br/xxviiianpet/anais/documents/AC395.pdf $>$. Acesso em: 08 jul. 2017.

SANTANA, C. M.; COSTA, A. R.; NUNES, R. M. P.; NUNES, N. M. F.; PERON, A. P.; MELO-CALVACANTE, A. A. C.; FERREIRA, P. M. P. Exposição ocupacional de trabalhadores rurais a agrotóxicos. Cadernos Saúde Coletiva, v. 24, n. 3, p.301-307, 2016. Disponível em: <http://www. scielo.br/pdf/cadsc/v24n3/1414-462X-cadsc-24-3-301.pdf>. Acesso em: 01 ago. 2017.

SILVA, E. A. Caracterização do processamento artesanal de produtos agropecuários em assentamentos rurais de Ilha Solteira - SP: das estratégias de produção à comercialização. Ilha Solteira, SP: Unesp, 2015. Originalmente apresentada como dissertação de mestrado, Universidade Estadual Paulista. Faculdade de Engenharia de Ilha Solteira. Disponível em: $<$ https://repositorio.unesp.br/bitstream/handle/11449/136085/000859300. pdf? sequence=1>. Acesso em: 10 ago. 2017.

SILVA, M. E. S.; BARONE, L. A. Associativismo e organização produtiva em assentamentos rurais: resistência social e políticas públicas na reforma agrária. In: Semana da Geografia, 12; Encontros de Estudantes de Licenciatura em Geografia, 7., 2011, Presidente Prudente - SP. Anais eletrônicos... Presidente Prudente - SP: Unesp. Disponível em: $<\mathrm{http}: / /$ www2.fct.unesp.br/semanas/geografia/2011/geografiaruraleagraria/ TCGRA08\%20-\%20Martha\%20Esthela\%20Santos\%20Silva\%20e\%20 Luis\%20Antonio\%20Barone.pdf>. Acesso em: 04 ago. 2017.

SOUZA, A. M.; VIEIRA, A. S. Estudo do rendimento operacional em operações de restauração florestal em áreas de matas ciliares. Instituto Pró-Terra, Jaú - SP, s.d. Disponível em: <http://www.institutoproterra.org.

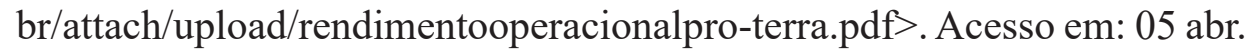
2017.

SOUZA, C. Si.; SOUZA, C. C. S.; VOSGERAU, M. Z. S. Conhecimentos e práticas na utilização de agrotóxicos e seu impacto na saúde de assentados 
de Jardim Alegre/PR. Revista Eletrônica Interdisciplinar, v. 6, n. 1, p. 62-72, jan.-jun., 2013. Disponível em: $<$ http://revistas.ufpr.br/diver/article/ view/33934/21168>. Acesso em: 02 ago. 2017.

UENO, V. A.; NEVES, M. Corrêa; QUEIROGA, Joel Leandro de; RAMOS FILHO, Luiz Octávio; OLIVEIRA, Laíssa Pacheco de. Estratégias de comercialização da agricultura familiar: estudo de caso em assentamentos rurais do estado de São Paulo. In: Simpósio sobre reforma agrária e questões rurais, 7., 2016, Araraquara - SP. Anais eletrônicos... Araraquara - SP UNIARA, 2016. Disponível em: <https://www.alice.cnptia.embrapa.br/ alice/handle/doc/1065665>. Acesso em: 09 ago. 2017.

VASCONCELOS, M. J. C. S.; BARBOSA JÚNIOR, Djalma Adão; STURZA, José Adolfo Iriam. Caracterização das atividades agroindustriais em assentamentos rurais vinculados a Associação Dando as Mãos no estado de Mato Grosso. In: Encontro Nacional de Geografia Agrária, 13., São Cristóvão - SE. Anais eletrônicos... São Cristóvão - SE: UFS, 2016. Disponível em: $<$ http://enga.com.br/anais/index.php $>$. Acesso em: 10 ago. 2017.

VERDEJO, M. E. Diagnóstico rural participativo: guia prático DRP. Revisão e adaptação Décio Cotrim e Ladjane Ramos. Ministério do Desenvolvimento Agrário, Secretaria da Agricultura Familiar, Brasília, mar. 2006. Disponível em: <http://www.mda.gov.br/sitemda/sites/ sitemda/files/user_arquivos_64/pageflip-2583697-3759191-DRP_-_Guia_ prtico-2649689.pdf $>$. Acesso em: 28 abr. 2017.

VERGES, N. M. Financiamento do setor rural: uma análise dos programas Procera e Pronaf e o caso dos assentamentos rurais do Pontal do Paranapanema - SP. Agrária, São Paulo, n. 15, p. 45-70, 2011.

\section{DESAFIOS DO PROGRAMA NACIONAL DE ALIMENTACÃO ESCOLAR (PNAE) COMO INSTRUMENTO DE FORTALECIMENTO DA AGRICULTURA FAMILIAR EM PEQUENOS MUNICÍPIOS}

\author{
Edmilson Carlos de Almeida Lopes Junior ${ }^{l}$ \\ André de Camargo Macedo ${ }^{2}$ \\ Ricardo Serra Borsatto ${ }^{3}$ \\ Leandro de Lima Santos ${ }^{4}$ \\ Vanilde Ferreira de Souza-Esquerdo
}

ReSUmo: A partir da promulgação da Lei 11.947/2009, as compras de alimentos destinadas para a alimentação escolar passaram a servir como instrumento de fortalecimento da agricultura familiar. Desde então, ficou estabelecido que ao menos 30\% dos recursos destinados para o Programa Nacional de Alimentação Escolar (PNAE) fossem utilizados na compra de alimentos produzidos pela agricultura familiar. Esse trabalho analisou a operacionalização desse programa em três municípios da região Sudoeste Paulista, objetivando compreender as dificuldades que pequenos municípios enfrentam em sua execução. Os resultados apontaram que, apesar de o programa ser considerado de grande relevância pelos atores locais, diferentes dificuldades emergem em função dos arranjos que se estabelecem em cada município. A pesquisa revelou que o comprometimento dos gestores públicos locais na promoção do diálogo entre os atores envolvidos na execução do programa pode ser considerado o fator decisivo para o sucesso do programa.

Centro de Ciências da Natureza, Universidade Federal de São Carlos (CCN/UFSCar). Graduando em Engenharia Agronômica. Bolsista PIBIC/CNPq/UFSCar. e-mail: ecalopesjir@gmail.com.

${ }^{2}$ Centro de Ciências da Natureza, Universidade Federal de São Carlos (CCN/UFSCar). Graduando em Engenharia Agronômica. e-mail: andre_macedo11@hotmail.com.

${ }^{3}$ Centro de Ciências da Natureza (CCN/UFSCar), Programa de Pós-Graduação em Agroecologia e Desenvolvimento Rural Universidade Federal de São Carlos (PPGADR/UFSCar), Professor Adjunto. e-mail: ricardo.borsatto@ufscar.br.

${ }^{4}$ Centro de Ciências da Natureza, Universidade Federal de São Carlos (CCN/UFSCar), Professor Adjunto. e-mail: leandrodelima@ufscar.br.

${ }^{5}$ Faculdade de Engenharia Agrícola, Universidade Estadual de Campinas (FEAGRI/UNICAMP), Programa de Pós-Graduação em Agroecologia e Desenvolvimento Rural Universidade Federal de São Carlos (PPGADR/ UFSCar), Professor Doutora. e-mail: vanilde.esquerdo@feagri.unicamp.br. 